Relations industrielles

Industrial Relations

\title{
Structure des salaires
}

\section{Gérard Tremblay}

Volume 5, numéro 6, mars 1950

URI : https://id.erudit.org/iderudit/1023333ar

DOI : https://doi.org/10.7202/1023333ar

Aller au sommaire du numéro

Éditeur(s)

Département des relations industrielles de l'Université Laval

ISSN

0034-379X (imprimé)

1703-8138 (numérique)

Découvrir la revue

Citer cet article

Tremblay, G. (1950). Structure des salaires. Relations industrielles / Industrial Relations, 5(6), 51-51. https://doi.org/10.7202/1023333ar

Tous droits réservés (C Département des relations industrielles de l’Université Laval, 1950
Ce document est protégé par la loi sur le droit d'auteur. L'utilisation des services d'Érudit (y compris la reproduction) est assujettie à sa politique d'utilisation que vous pouvez consulter en ligne.

https://apropos.erudit.org/fr/usagers/politique-dutilisation/ 


\section{Bulletin des relations industrielles}

Volume 5, numéro 6

QUÉBEC

mars 1950

Le cinquième Congrès des relations industrielles de Laval

\section{STRUCTURE DES SALAIRES}

Le cinquième Congrès des relations industrielles sera consacré à l'étude du vaste problème de la rémunération du travail. Le thème que ses organisateurs ont choisi, «Structure des salaires》, ne rend peut-être pas justice à toutes les conférences qu'il veut à la fois annoncer et contenir, mais il a cette qualité de bien indiquer qu'il est centré sur le salaire, sa formation, ses modalités et ses variations. S'il est vrai qu'il y a une structure des salaires, il faut alors admettre qu'il y a une technique des salaires. Les salaires varient au sein de l'entreprise, non pas toujours au gré de l'ouvrier ou du patron mais sous l'influence de facteurs économiques susceptibles d'être analysés. Même si le salaire basique est fixé dans une entreprise, il reste à établir les relations entre les fonctions ou les tâches; les unes sont plus difficiles ou plus pénibles que les autres et postulent une rémunération concordante. On aura donc une étude sur les éléments de contrôle de la rémunération du travail.

Beaucoup d'industries se prêtent à la divisibilité des opérations et partant au travail à la châ̂ne. Dans le but d'accroître la productivité du travailleur comme de le rémunérer proportionnellement d sa valeur on maintient encore, malgré ses inconvénients d'ordre humain, le système de travail à la pièce. Comment doit-il être organisé pour assurer d'une part une production accrue et garantir d'autre part les droits de la personne humaine? Des conférenciers traiteront de façon objective de cette technique de la rémunération.

Dans une économie de libre concurrence et d'entreprise privée, les employeurs, aidés du concours d'ingénieurs spécialisés, s'évertuent à trouver des moyens d'augmenter la production tout en réduisant le coût, non pas seulement par un choix judicieux des machines et un aménagement scientifique des procédés de travail, mais aussi par la mise en oeuvre de systèmes très variés de primes au rendement. C'est bien là la reconnaissance du caractère humain du travail et de la nécessité de faire appel à l'intelligence de l'homme et à sa libre volonté si l'on veut réaliser mieux et plus grand.

Précisément pour ne pas laisser dans l'ombre le caractère humain du travail et de sa dépendance de la loi morale, nous avons invité un rapporteur à nous rappeler les critères sociaux et moraux du juste salaire. Le salaire n'est pas une marchandise même s'il subit l'influence impérieuse du marché; il est surtout le moyen normal pour une multitude d'hommes de subvenir à leurs besoins et de réaliser à tous égards leur perfectionnement.

L'Economique nous ramènera aux études positives nécessaires. Comment expliquer le phénomène de la variation des salaires entre unités d'une même industrie ? Quels sont les rapports entre la grande, la moyenne et la petite industrie dans un même secteur de production ? L'indice des salaires doit-il épouser les courbes du développement industriel de chaque unité de production; ou encore doitil varier selon la situation géographique de l'entreprise ou selon qu'elle se développe dans des centres urbains ou ruraux? S'il doit y avoir dans ces cas un certain décalage des taux de salaires, existe-t-il, en dehors de l'expérience, des normes qui permettent de le déterminer sans nuire au bien commun?

Et que dire de la variation des salaires entre industries diverses? Quelle est la cause économique de ce sectionnement entre industries aristocratiques et prolétariennes? Quelle est la part du monopole, du jeu de l'exportation et de l'importation, de la pression syndicale, de la nature du produit, des difficultés techniques du travail, de la mécanisation, des risques de chômage, de la tradition même, dans cette dentelure des taux de salaires des métiers et occupations des différentes industries?

Des conférenciers nous donneront le résultat de leurs recherches et tâcheront de répondre d ces questions.

Sans viser à la conquête de l'absolu, nous essaierons enfin de nous demander s'il existe des lois économiques immuables pouvant expliquer la formation des taux de salaires et leurs variations. Si ces lois existent ou ont tendance à se manifester, on nous expliquera comment l'homme réussit d̀ les brimer et à les soumettre à sa propre loi qui, dans un monde où l'on reconnaît la primauté de la personne humaine, peut devenir une loi de justice et de charité.

GÉrard Tremblay

Nous avons l'assurance que la participation d̀ ce cinquièn.e Congrès des relations industrielles sera aussi nombreuse et intéressée qu'd celui de l'an dernier. Théoriciens et praticiens des questions économiques et sociales, patrons, ingérieurs, chefs syndicaux, fonctionnaires et administrateurs des lois du travail, tous trouveront intérêt et profit dans les discussions libres qui les suivront. On pourra lire ailleurs les informations relatives au Congrès; on fera bien de hater son inscription au Département des relations industrielles, Faculté des sciences sociales, 2, rue de l'Université, Québec. 